\title{
Globalisation, collaboration, and indigenous alcohol abuse
}

\author{
Thomas W. Piggott
}

\begin{abstract}
This study was conducted under the supervision of Professors Jacqueline Murray ${ }^{1}$ and Alastair Summerlee ${ }^{2}$, ${ }^{1}$ Department of History, College of Arts; ${ }^{2}$ Department of Biomedical Sciences, Ontario Veterinary College University of Guelph, Guelph, Ontario, Canada
\end{abstract}

\begin{abstract}
Alcohol abuse is attributed to four percent of the global burden of disease and associated with over 60 medical conditions. This burden is borne disproportionately by the indigenous peoples of our world. Two such indigenous populations, albeit far from one another, who are suffering from alcohol abuse are the San in Botswana and the First Nations in Canada. Both marginalised populations have high rates of alcohol abuse; however, there is a clear need for more research into the epidemiology. The public health response to alcohol abuse in indigenous populations is at a different stage in Canada and Botswana. In Canada, alcohol abuse among the First Nations has been on the agenda of public health since the release of the Indian Relations Paper in 1975. In Botswana, alcohol abuse among the San has yet to be recognized- the government response has been blind to ethnicity. This paper examines the similarities and differences between alcohol abuse issues, providing evidence that increased collaboration would lead to benefits for both populations. Neither side, those responsible for the public health of the San or First Nations, has an impeccable record - both sides could learn much from the successes and failures of the other, and other indigenous populations suffering from alcohol abuse globally.
\end{abstract}

$\mathrm{O}$ ne of the greatest public health concerns facing our world is alcohol abuse. Four percent of the global burden of disease and over 60 medical conditions are attributable to alcohol abuse [1]. What is most disturbing about these astonishing figures is that they are largely preventable - alcohol abuse is ultimately a controllable and supposedly 'self-inflicted' condition. For those affected, however, the story of alcohol abuse is a much deeper emotional and personal issue than global numbers can convey. Abusers become rapidly dependent, trapped in a cycle not only difficult to break, but also highly destructive to work and family life. Genetic determinants to alcohol abuse are well documented [2] and beyond genetic predisposition, people raised in an alcohol abusing family or community environment are more prone to be afflicted themselves. Alcohol abuse is a complex public health issue with many causes and ramifications globally.

Indigenous peoples have a higher rate of disease attributed to alcohol abuse than those of other populations. The First Nations in Canada and the San in Botswana are two such populations severely affected by alcohol abuse. Although they are distinct and geographically distanced populations, many alcohol abuse parallels may be drawn from their respective epidemiological and socio-economic contexts. Despite the parallels, the responses of the public health authorities and governments have been vastly different. This paper will explore these parallels and the different responses as evidence of the need for increased collaboration on alcohol abuse research, programs and policy planning for indigenous populations.

Alcohol abuse is indeed one of the most significant health concerns among a multitude of issues that plague the world's first peoples. It is critical that public health planning target its programs to unique populations. However, this need has thus far been neglected for many of the world's indigenous populations. Even in areas with extensive public health activity, it is not always reaching the target population. While the inferior state of health in some indigenous populations has caught the attention of their respective governments, for many others there has yet to be an appropriate response .

Behind these indigenous health issues, in particular alcohol abuse, reside historically rooted social, economic and political marginalisation. The wide reaching social, economic, cultural and political implications of alcohol have been observed in European society for centuries [1]. European colonialism brought increased accessibility of alcohol to global indigenous societies, who may have already had access to alcohol, but not in such high quantities. In this way, alcohol abuse became a problem among the First Nations in Canada and the San people in Botswana.

The First Nations in Canada are diverse indigenous populations, grouped under a common name on the basis that they inhabited Canada prior to European contact. Their lifestyle changed rapidly after coming into contact with Europeans and has evolved into a state in which numerous health and social issues plague their communities to the 
present day. For over a century, the Canadian government's response has focussed on assimilation [16]; the First Nation's health problems, including alcohol abuse, would be solved if they would just become 'Canadian'. More recently, specific health programs have emerged that incorporate the perspectives of the First Nations themselves. Despite the changing response, alcohol abuse is still the cause of significant health and development concerns.

The San in Botswana have experienced marginalisation dating back to before European contact. Once a nomadic people, they have been subordinated for centuries - first to African Bantu pastoralists and then to colonialists. Many in their current fragmented population turn to alcohol to forget about their sorrows [6]. Unlike the Canadian government's hands-on approach, the government of Botswana has taken an opposite tack, ignoring the San's cries for help and their longing to be acknowledged as an indigenous people. As a result of this wilful blindness, there has been no public health response to alcohol abuse specifically directed to San people.

The widespread globalisation that has occurred since World War Two has resulted in the world becoming increasingly interconnected [3]. The implications of this interconnectedness to human health are not yet entirely clear, however, several common trends found in the literature on globalisation and public health have interesting applications to indigenous alcohol abuse issues. The World Health Organization, among other international bodies, developed as a result of globalisation. They are the best suited to respond to indigenous alcohol abuse on a global scale.

Though indigenous communities around the world are unquestionably unique, many parallels may be drawn concerning the factors that contribute to alcohol abuse. For this reason, the isolated policy and program planning that currently exists at the national level could benefit greatly from multilateral collaboration to more effectively facilitate the sharing of information.

\section{The SAN IN BotSWANA}

The San are an interconnected but distinct people inhabiting Botswana, Namibia and South Africa. Having originally lived nomadically as hunter-gatherers, the San have inhabited this southern African region for millennia. There is currently a general acceptance of the similarity between different San populations, following an international conference where the name "San" and a degree of unity were recognized and accepted [4].

A culture and people once adorned with tradition, song and dance, much has been forgotten as a result of a process of subordination and marginalisation that began centuries ago. When the European colonialists settled on farms in the region, the San became sub-subservient and the region's most marginalised African population. Even today, in Botswana, which is a successful democracy in comparison to many of its sub-Saharan neighbours, racism towards the San is rampant. The continued racism experienced by the San is accompanied by an ever diminishing standard of living.

\section{History of the San and Alcohol}

Prior to independence a large portion of the San population had been living according to traditional ways. They were relocated, however, because their land was expropriated to create the Central Kalahari Game Reserve, and they were forbidden to hunt in the park. In the remote San villages that were created, the living conditions are inferior to those found among the rest of Batswana (Botswana citizens). There are frequent food shortages that result in widespread malnutrition. The remoteness also necessitates long distance travel for healthcare and other basic needs. Little economic opportunity exists for the San apart from some farming and cattle-rearing or fishing. All of these circumstances, combined with a reliance on sporadic living stipends from the government, make for a dismal environment and have driven many San to alcohol abuse.

Macdonald and Molamu call alcohol abuse among the San an epidemic [5]. The extent of the problem is not exactly known, however, extensive personal accounts and anecdotal research have identified alcohol abuse as a significant issue which is ravaging San communities. The issues of alcohol abuse in the San are very complex and interconnected, given their history of social and economic marginalization. Alcohol was traditionally fermented from wild fruits, berries and honey, and due to a lack of potable water, was reserved for ceremonies and rituals [6,7]. Upon Botswana's independence in 1966, alcohol became available to the San in volumes never before experienced [5]. The effect was overwhelming to a people not historically adjusted to extensive alcohol consumption.

\section{Contributors to Alcohol Abuse Issues Amongst the San}

Factors that led to increased alcohol consumption are numerous and vary widely depending on the population of San involved, their geographic location, age and gender. Many motivating factors revolve around a general sense of acculturation and loss of identity [8]. The loss of identity and culture are the result of assimilation that has been systematically occurring due to the government's programs to relocate the San from their ancestral land [9]. In the relocated environment, many San feel a sense of inferiority and are embarrassed by their heritage; some even deny they are San [10]. For many, this sense of inferiority has translated into alcohol abuse. Some San feel the need to drink to overcome low self-esteem, to fit into non-San social circles and to find friendship and romantic relationships [5,11]. To feel brave and empowered in this negative environment, many San also turn to alcohol [8].

Poverty and economic marginalisation are also significant motivators for alcohol abuse. It may seem ironic that poverty is a motivator for alcohol abuse, as the cost of alcohol is so high, however, the San become trapped in a cycle. Abusers may go days without drinking but when 
money does arrive, it is rapidly spent on alcohol [6]. Many San are forced to choose between spending their money on alcohol or food [6]. While food quells their incessant hunger, alcohol makes them feel good and forget their hunger $[4,6]$. This creates a vicious cycle that will continue unchecked into the future without significant public health intervention.

Another factor that contributes to alcohol consumption is the cultural kindness of the San [6]. The San once and still do feel, a great sense of compassion and community, which sometimes leads them to consume alcohol. As one San woman astutely put it [8]: "I have taken some drink on account to help her out [her being a Herero woman who came to sell beer on pension day]. The poor woman had gone through all this trouble ". This sense of compassion and community is frequently taken advantage of by those who sell alcohol [8].

Pubs and bars are frequented by San, however, local Shebeens provide a more accessible and unregulated source of alcohol. These unlicensed alcohol vendors sell a homebrewed drink from their homes [6]. Typically run by women, and providing a source of additional household income, alcohol may be purchased at any time [6]. Shebeens may sell alcohol on credit, which exacerbates the poverty of their customers [7]. The government has taken a very lax attitude towards the tens of thousands of Shebeens across the country and, with respect to the San, has even stated that they are an important source of local revenue. However, Shebeens frequented by the San, in communities where they have been resettled, are often run by people of other ethnicities, and therefore do not in fact benefit the San [6]. Beyond that, local Shebeens do not benefit the community because there is only an internal exchange of money. Moreover, it has been reported that the Shebeen businesses actually operated by the San are not as successful due to their cultural practices of sharing and reciprocity - principles which do not equate to economic success [12]. Shebeens are a significant source of alcohol distribution in Botswana and particularly in San communities. Some of them can sell more than 50 litres of home brewed beer per day [6]. In some San communities where there are no permanent Shebeens, temporary mobile vendors may arrive monthly, coinciding with the distribution of drought relief or welfare cheques [6].

The San suffer inferior health as a result of alcohol abuse. Health professionals have reported that San who abuse alcohol suffer a general self-neglect and poor personal hygiene [13]. These factors may contribute to any number of health issues, but the realconsequences have not been studied. Self-neglect, is a serious issue among San suffering from a chronic condition; self-neglect makes them less likely to take medications as directed [13]. HIV-positive San who abuse alcohol may forget to take their Anti-Retrovirals (ARVs) [14]. Inconsistent use of ARVs decreases their efficacy and can cause resistance and the need to move to more costly second or third-line treatments.
Alcohol abuse has other effects on HIV. This is a worrisome issue in Botswana, where HIV rates are the second highest in the world at approximately $39.1 \%$ in adults [14]. Alcohol abuse raises the risk of engaging in risky sex and contracting HIV. A study conducted in five regions of Botswana found that alcohol consumption is consistently associated with unprotected sexual behaviour, heightening the risk of HIV transmission [15]. HIV has been unofficially reported to be less prevalent in the San [9], however, it could increase with the widespread abuse of alcohol.

A further impact of alcohol abuse on the San, with grave health and socioeconomic implications, is the changing status of women. Traditionally, the San demonstrated a system of gender equality; however, changes to their gender system have accompanied their assimilation into modern Botswana society and the increasing abuse of alcohol [9]. Alcohol abuse has contributed to a surge of gender-based violence and child abuse $[4,6,12,13]$. It has also been reported that alcohol abuse has led otherwise law-abiding San citizens to an alcohol-induced sense of adventurism and to poaching game [13].

Alcohol abuse has very serious intergenerational effects. Witnessing the alcohol related problems of their parents damages San children, trapping them into the situation and practices of their parents. The nonexistent support systems for children make succeeding in school a challenge [8,13]. San children are [8]: "drifting and helpless. Alcohol seems to be their only refuge. The daily struggle to get something to eat and drink consumes all their energies, and school is an irrelevance, something outside their daily experience and interest. ". San children who abandon their schooling, experience barriers to employment and turn to alcohol to quell their anguish.

San parents used to be very involved in the education of their children. This role has changed as government mandated schooling requires children to travel very far and often board at school [10]. The children return home only briefly over school holidays. It is very difficult for parents to accept the loss of their children, often leading to despair and drinking.

\section{Addressing Alcohol Abuse Amongst the San}

Many San are aware of the alcohol problems plaguing their community [10]. The outright ban of alcohol is a much discussed solution. The government will not take the lead on these alcohol banning initiatives as it prefers not to interfere in alcohol regulation. Grassroots banning initiatives and informal policies in the Ghanzi and Kgalagadi districts, both with large San populations, have gathered some support and momentum but have had almost no impact [7]. This is likely because these informal banning initiatives have had very little effect on the supply of alcohol, which continues to be readily available.

A new avenue for alcohol education may be the development strategy being promoted by the Botswana government, via Community Based Natural Resource 
Management projects (CBNRMs) [7]. CBNRMs aim to empower the community by allowing them to decide how they manage their land and resources. Applicants create a community trust, which oversees the projects and decides how any money raised, through the management of their own resources, is spent on local development projects [7]. This form of organisation is the transparent and guards against corruption [10]. If the community development trusts were not in place, one might postulate that money going to an individual from natural resource management, might end up fuelling alcohol abuse problems. According to Gujadhur, the role of the community trust could extend beyond this primary management and fund allocation role into the body that oversees public health projects such as alcohol education campaigns [7]. Other development initiatives undertaken by the CBNRMs would also help to reduce both poverty and alcohol abuse.

As can be seen, the roots of alcohol abuse travel much deeper than alcohol availability and education. Public education campaigns on the effects of alcohol abuse are not likely to have great impact. The San know firsthand the effects of alcohol abuse; they need only look around their communities and their own family. These underlying issues point to the need for a multi-sectoral development approach to heal the wounds of the past and to form the bonds of the future. There needs to be immediate action to prevent the further destruction of this already weakened people [6], "what we are seeing here is the systematic destruction of a people and their culture through alcohol abuse".

\section{The First NATIONS IN CANADA}

The indigenous peoples in Canada consist of many distinct populations spanning from the $49^{\text {th }}$ parallel to North of the Arctic Circle. In the past, these included populations that led both sedentary lifestyles (e.g. Iroquois First Nations) and nomadic lifestyles (e.g. Algonquin First Nations, the Inuit). While their grouping as one people in various political contexts and legislation reveals an ignorance to the diversity of these populations, discussions in this section will focus on issues at a national level and, as such, will refer to general trends among these connected populations.

There was no evidence of alcohol consumption among First Nations prior to seventeenth-century contact with Europeans. Consumption of other substances, such as tobacco, was well recorded. Early contact with Europeans centred on trade, with First Nations trading furs and tobacco for firearms and alcohol. Alcohol trade became a priority for First Nations after their introduction to this addictive substance. The "firewater myth" spread the notion that the aboriginal people were inherently more susceptible to alcohol abuse. This myth endures today, despite the absence of biological evidence to support it [16].

The worst effects of alcohol abuse are often felt by the wife and children of abusers. This has been observed in alcohol abuse trends in all populations, however, it had notable effects on the aboriginal families at the time of contact. Alcohol tore apart families and communities, impeding opportunities for development in the new Canadian society.

\section{History of the First Nations and Alcohol Abuse}

Canadian indigenous peoples gradually lost their important role in the fur trade, thus diminishing their ability to procure alcohol [17] a substance that was now entrenched in their communities. The Hudson's Bay Company had been instructed to move west, away from the American colonies, in an attempt to promote more peaceful British-American relations. This geographically and politically removed the First Nations from the fur trade.

Confederation did not improve the situation of the First Nations people. One of the first major acts of the Canadian government was the Indian Act of 1876. Blatantly an assimilation policy, the Indian Act made the sale and possession of alcohol by "status Indians" illegal. Those who relinquished their "Indian" status were permitted to purchase alcohol. Despite the prohibition, alcohol was not difficult to obtain through bootleggers [17]. The fact that "ex-Indians", who had relinquished their status, were permitted to purchase alcohol was seen as an incentive to become Canadians, and thus assisted assimilation priorities of the Canadian government. In other words, alcohol was a tool of assimilation. First Nations people across Canada found the Indian Act both patronizing and demoralizing, and believed that equality must be obtained [18]. Many campaigns on indigenous rights revolved around equality without assimilation, despite the fact that this was not the government's intention.

The assimilation policy underlying the prohibition of alcohol for First Nations people continued well into the twentieth century. After the Second World War, federal policy shifted to equal access to alcohol, arguing this would better promote assimilation because discrimination by way of racial prohibition was seen as fuelling aboriginal identity and resistance to assimilation [18].

Under Trudeau's leadership, in the late 1960s, Jean Chrétien, then Minister of Indian Affairs, published the 1969 White Paper. This controversial policy document encouraged "participation of the Indian people in Canadian society..." and "equal status, opportunity and responsibility"; essentially diminishing privileges for those with "Indian status" [19]. First Nations leaders saw this as another assimilation attempt. These sentiments were reflected in the "Red Paper", the response of First Nations Leader Harold Cardinal to the White Paper. The White Paper was quickly withdrawn; its weakness was the absence of input from First Nations people in a document intended to benefit them. This was a trend that had reoccurred many times in the past in policy planning for the First Nations of Canada [18].

Until the 1970s, planning surrounding alcohol abuse focussed on prohibition and substance control. "Liquor prohibitions were part of an assimilation process that was 
brutally ineffective, as in the case of residential schools" [17]. Following the White Paper, more emphasis was placed on health, rather than merely on the control of alcohol. This created the opportunity for programs such as the Native Alcohol and Drug Abuse Program, allowing the focus to shift to a more preventative approach to alcohol abuse, and shifting attention to education and socioeconomic factors.

Ultimately, the greatest shortcoming of these efforts to improve alcohol abuse in the First Nations was the lack of input and responsibility by First Nations people in finding solutions. As Chief Lawrence Joseph of Saskatchewan said; "When governments have tried to prescribe the treatment for First Nations, it has not worked. The power and financial capacity needs to be put in the hands of First Nations communities" [20].

In 1975, the Indian Relations Paper emphasized just that, the necessity of incorporating the First Nations and their perspectives in the planning and implementation process for their own healthcare. Subsequent papers, policies and programs increased aboriginal participation in their own healthcare. Today, much of healthcare and the management of issues such as alcohol treatment, is in the hands of indigenous communities and reserves that are, in theory, being given the tools to succeed.

As the issue of alcohol abuse varies considerably among different First Nations populations in Canada, there is a diversity of responses to alcohol abuse across Canada. There are several communities and reserves where alcohol has been prohibited, and others where plebiscites have answered "no" to prohibition. The efficacy of these programs is constantly being evaluated. Some sentiments, reported anecdotally, favour the use of prohibition policies [21]. These policies, implemented locally, can at the very least be an initial step to combat alcohol abuse.

\section{Contributors to Alcohol Abuse Issues Amongst the First Nations}

Currently, alcohol abuse among the First Nations is one of a multitude of health issues plaguing their people, families and communities. Tuberculosis, obesity, infections and Type 2 diabetes are all significantly higher in First Nations people than in the rest of the Canadian population. Alcohol abuse remains a grave concern today and is among the most pressing health related issues for First Nations. Alcohol abuse is such a concern on some reserves that Health Canada delayed distributing alcohol-based hand sanitizers during the recent $\mathrm{H} 1 \mathrm{~N} 1$ pandemic preparations, out of fear that they would be ingested [22].

Recent data has shown that the total amount of alcohol consumed per capita on First Nations reserves is lower than in the rest of Canada [23]. But, despite the fact that the volume of alcohol consumed per capita is lower, it is consumed by fewer people, those people with alcohol abuse issues. Alarmingly, $16.0 \%$ of First Nations people on reserves are alcohol abusers; more than double the proportion for the non-aboriginal population [23].
Another worrisome issue is the changing gender dynamics of alcohol abuse. Despite alcohol abuse still being more common in men, a growing concern is the proportion of First Nations women who abuse alcohol. Roughly three times more women abuse alcohol on reserves compared to non-aboriginal women [23]. The alarming state of alcohol abuse in First Nations women is a recent phenomenon and may be an indication future direction. Consequently, this issue will require particular public health attention.

To reduce alcohol abuse it will be necessary to improve opportunities and economic prospects on reserves. An increase in income of $\$ 1,000$ per year per person living on a reserve has been correlated to a decrease in consumption of 0.297 litres (pure alcohol equivalent) [24].

While actions to improve the socioeconomic situation of the First Nations are given the highest priority, the more pertinent question for public health is what can be done in the meantime. Education about alcohol abuse and the tools to abstain and minimize consumption may be helpful, although they need to be tailored to specific communities. They must also be cognoscente the socioeconomic difficulties and the difficulty of living in an environment where abuse is an issue.

Treatment is another response that may help reduce the abuse of alcohol. Treatment will help reduce the impact on individuals, but will also reduce visible abuse in the community. Treatment depends on the severity of abuse, can be a timely intervention. The most important element of treatment is continued abstinence after returning home from a treatment centre or hospital. This requires a supportive environment. According to Chief Darren Blaney of Hamolko Reserve north of Nanaimo, B.C., "Many have to leave to go into treatment. Then when they come back, their neighbours and relatives are drinking and convincing you to drink, so they get back into their [drinking] cycle shortly after" [20]. Without an environment that supports abstinence from alcohol it is difficult for individuals to persist in their recovery and not relapse into abusing alcohol.

In the short term, there has been renewed interest in the old solution of complete prohibitions. One Inuit CBC News reader from Behchoko, Nunavut commented [25]: "Prohibition is not the final answer, but it will help as a first step towards giving a small community a chance to get on the right track. The reason prohibition does not work is simply the fact that people lack the ambition to work towards a healthy solution". Despite the potential effectiveness of prohibition, proposals are rejected as having little effect on reducing alcohol availability. A community member from Behchoko, Nunavut raised the point that [25]: "sure there will be bootleggers, just like drug dealers". In other words, though prohibition may not eliminate the availability of alcohol, by making its consumption illegal, it will become socially unacceptable to drink. It is easier to enforce prohibition on isolated reserves or in northern communities, because the influx of alcohol can be more easily controlled, given that goods are brought in by plane once a week. Such 
is the case in Kugluktuk, Nunavut, where prohibition has been a topic of discussion for some time [26].

Ultimately, according to Chief Daren Blaney [20], "for people to sober up it is not going to be one magic bullet, it has to be a whole combination of support systems in place". Thus, while keeping the improvement of socioeconomic factors at the top of the agenda, it will be necessary to determine which programs are most effective and to incorporate First Nations representatives in policy planning.

\section{GLOBALISATION}

Globalisation is an ambiguous concept. Though most academics agree it is rapidly occurring, its criteria and ramifications are still uncertain and contentious. Typically referring to an increased "movement of goods, people, information, and ideas", globalisation is propelling unprecedented change in our modern world [27]. Globalisation has brought about significant changes to disease and the public health response. In terms of alcohol abuse, the effects of globalisation can be narrowed to three main categories: the effects of increased economic integration [28], increased capacity to respond globally to health threats that cross borders [3] and increased interrelatedness of the global population. These effects are influencing, for better or for worse, alcohol abuse in the indigenous peoples.

Economic integration has seen the manufacture and distribution of products, including alcohol, escalate in much of the world. For the aboriginal people on reserves and the San in rural settlements, the effects of increased production and faster transportation have been bleak. Alcohol may arrive by plane, $4 \times 4$ trucks or any number of ways, to reserves or settlements that were once isolated. Unfortunately, increased availability to these two populations, which previously have had little access to alcohol, has led to startling levels of abuse [32].

The economic implications of globalisation, however, are not all this bleak. The benefit of economic integration, frequently touted by proponents of globalisation, is a rise in income for the world's poorest people. A rise in income is a consequence of the increase in opportunities for trade. If this is an accurate portrayal of what has, or will, happen with globalisation, then this could reduce abuse of alcohol. A rise in income in First Nations populations has been correlated with a significant decrease in consumption of alcohol [24].

The pertinent question is whether the indigenous populations will actually experience a rise in income. The research here is not as optimistic. David Rieff argues that the developing world of sub-Saharan Africa has largely missed out on the benefits of the first round of globalisation [29]. If this is the case, then how will the indigenous populations of Africa or elsewhere, often deemed to be the "fourth-world", ever have the opportunity to develop?

\section{Globalization and the Global Response}

Globalisation has seen the creation of international bodies, such as the World Health Organisation, and increased their capacity to respond to global health issues such as alcohol abuse. Though alcohol abuse was on the agenda of the nascent WHO, interest was quickly lost. However, in the 1970s, alcohol abuse resurfaced on the agenda of the WHO [30]. There have since been continued attempts towards global alcohol control policy have continued since then. In the late 1990s, the World Health Organization's Programme on Substance Abuse produced a comprehensive document for communities and policy makers on the topic of alcohol abuse in indigenous populations. Although useful to raise awareness of issues of alcohol abuse in indigenous populations, the report did fail to recognize the diversity of factors contributing to alcohol abuse. A new direction that may provide health gains in terms of alcoholism for the indigenous populations discussed in this paper is that of collaboration on health policy, and research challenges and success. The issue requires a permanent body providing a forum for collaboration between indigenous people and their governments. This would be a perfect role for the WHO and a direction the Program on Substance Abuse should take.

This type of collaboration on the issue of alcohol abuse is supported by the third factor of globalisation, the nature of our increasingly interconnected global community. People are more interrelated people due to technological advances, instantaneous global communication and rapid transportation. People and governments can come together to discuss similar issues, in terms of challenges and successes, so that they may learn from one another and build upon shared knowledge.

\section{The Need for Collaboration}

Alcohol abuse among the San and the First Nations is a prime example of an opportunity to collaborate. The similarities and differences between the issues that underlie alcohol abuse in these two populations separated by half of the globe could be important to future public health planning (see Figure 1 for factors affecting alcohol abuse in the First Nations, the San, and factors that overlap between the two populations). By sharing experiences, everyone would have the opportunity to learn how programs and policies have played out in similar, albeit distinct, environments.

Both the San and the First Nations have felt the iron fist of multiple forms of colonisation. They have experienced centuries of marginalisation that persists today, and they lack the economic opportunity to dig their way out. Attempts at assimilation have led to a period of unprecedented acculturation for these populations. As a result of all of these hardships, they are today experiencing alcohol abuse issues that are tearing up their communities. The similarities are so clear that the need to collaborate trumps any geographical differences between these peoples. 


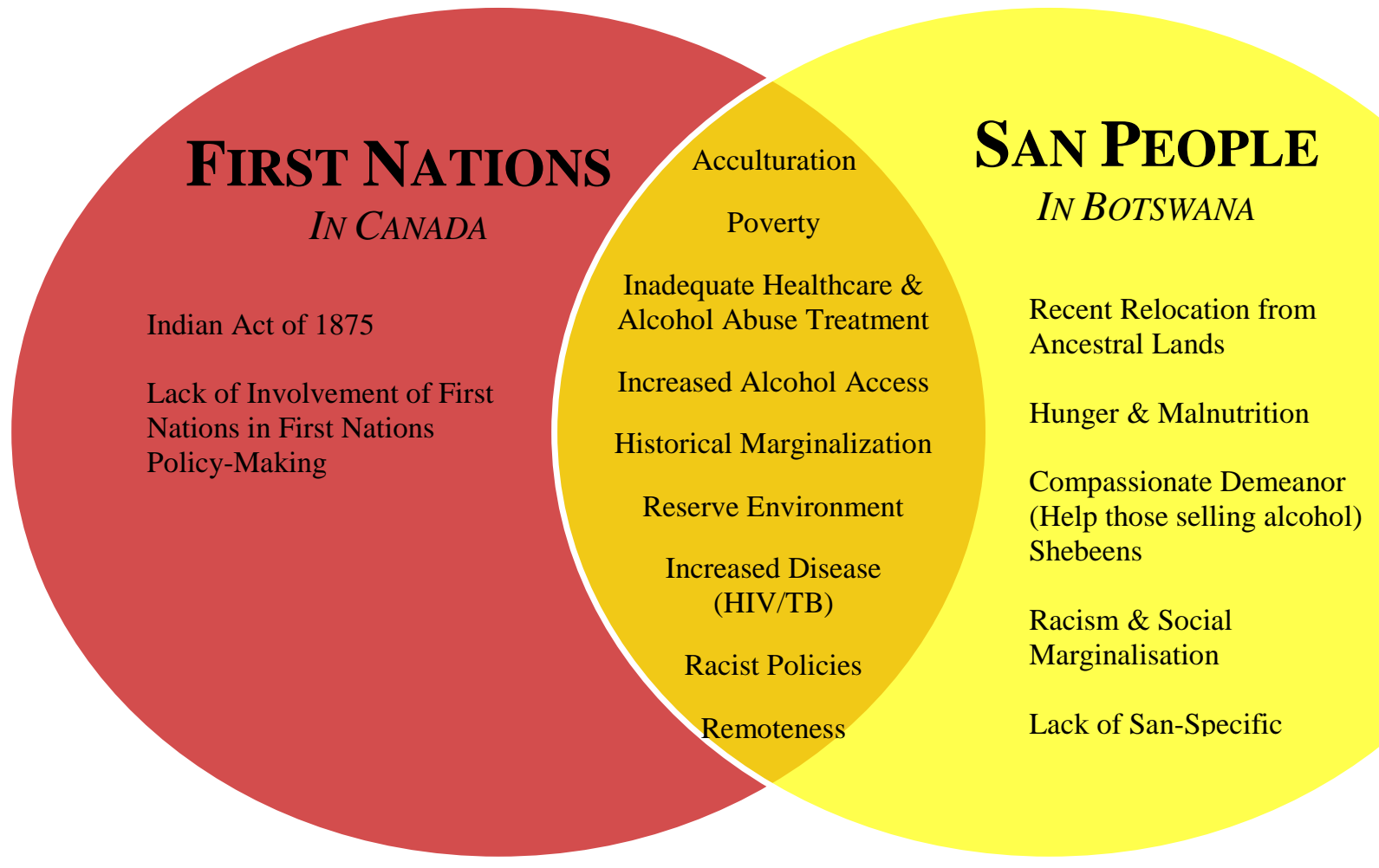

Figure 1: Venn Diagram showing the factors affecting alcohol abuse amongst the First Nations in Canada (red), the San People in Botswana (yellow), and the factors that overlap (orange). Elaboration on the factors, and their references is provided in the article.

Despite the similarities, the respective leadership of the San and First Nations have responded very differently. The First Nations have survived decades of assimilation policies and now have the opportunity for input and to manage programs to solve their issues themselves. The San still fight for recognition in a country that has not acknowledged them as an indigenous people. Their programs and policies are the same as for the rest of the Batswana. Is the response of one government better than the other? That is an impossible question to answer due to the differences in contexts. But, collaboration could bring a learning experience for both parties, as well as for any other indigenous parties that might benefit from participation.

The different responses in Canada and Botswana have resulted in unique gains and problems. Great benefit may come from learning about these, so that the gains could be maximized and problems averted. In this way both parties could benefit. As the San have yet to be recognized, one might argue that the First Nations in Canada have more to share and less to learn than the San. Is this really true? After all, among the good advances the First Nations have experienced from so-called recognition, have also arisen many harmful and racist policies. It would be heavily contested to say that recognition has only served the First Nations in Canada for the better.

A clear example of the opportunity to collaborate is on the issues surrounding the creation of residential schools for First Nations children that resulted from assimilation focused indigenous policies such as the Indian Act. These schools, though potentially well intentioned, resulted in the most abhorrent situations of abuse and discrimination, which are only now being recognized and reconciled [31]. Alcohol abuse among many First Nations adults is related to their experience and the trauma of abuse in these residential schools.

In Botswana, a similar concept of San schools is being explored and favoured by many San. In neighbouring Namibia, a government-run San school is already operating. The idea is favoured among the San in Botswana as a means of teaching San language and culture, which is not taught currently in the mainstream school San children attend. ${ }^{10}$ Extensive knowledge of experience of residential schools in Canada would benefit the San as they consider what course to take.

Sharing the success and challenges of other programs and policies would provide the benefit of not having to "learn the hard way". In Canada prohibition for the First Nations has been attempted in various contexts, by various levels of government with both positive and negative effects. Contrastingly, in Botswana, this sort of policy has not been tested - the Botswana government has not even recognized the plight of the San [6]. The benefit that would come from the collaboration of the San and the First Nations, among other indigenous populations around the world suffering from indigenous issues of alcohol abuse, cannot be gauged 
merely in theory. Only actively engaging in collaboration will reveal the true benefits.

In today's era of globalisation and increasing interconnectedness, collaboration is inevitable. For the 'fourth world' indigenous people, who are missing development opportunities due to long standing issues feeding alcohol abuse, this should be accelerated as quickly as possible to enhance comparative and collaborative approaches to reducing alcohol abuse. Enough suffering has occurred as it is. It is time to bring the attention of public health officials and governments to the challenges faced by indigenous populations globally and the benefit that could come from collaborative and self-direct problem-solving.

\section{CONClusions}

Impeding development, feeding a loss of culture and identity, tearing up families, raising the suicide rate and other mental health problems, these are just a few of the realities of alcohol abuse among the San in Botswana and the First Nations in Canada. Though self-inflicted, the corrosive effects of social, economic and cultural marginalization play heavily on alcohol abuse issues. Public health agencies and governments need to search for the best health program and policy solutions to alcohol abuse in indigenous populations. One way is to learn about the successes and challenges of others.

Alcohol abuse in the San is of epidemic proportions, and the public health response has been one of ignorance. This stems from the government's wilful refusal to recognize the San as an indigenous people. The government has ignored differences in ethnicity promoted a united, anti-racist Botswana; however, racism against the San continues. The public health response will need to go beyond treatment and education to target socio-economic factors, as well.

The Indian Act, social societal segregation and economic marginalisation have been exacerbated alcohol abuse among the First Nations. Improvements will only now begin, with the acknowledgement of socio-economic factors and the incorporation of the First Nations, themselves, into the health planning processes.

These two situations - geographically, historically, politically and culturally distinct - have much in common. Despite the common ground, the respective governments and public health authorities have responded very differently to the issues. Much can be learnt from this difference and much can be gained from collaboration. Whether the collaboration would be best between governments, public health agencies or the indigenous peoples themselves is unclear. Similarly, the form and forum of collaboration would need to be determined. It would appear to not make sense to limit discussions to Canada and Botswana, since there are many indigenous societies elsewhere with similar problems of alcohol abuse. Some comparative research on alcohol abuse has already been done between the indigenous populations in the United States and New Zealand. ${ }^{32}$ This suggests that multilateralism, on a global scale, would be beneficial. The best forum for such collaboration would be the World Health Organization and the Substance Abuse Program, already experienced and in place to deal with alcohol abuse on a global scale.

Whether this collaboration will be facilitated quickly depends on the World Health Organization, the national governments and the indigenous populations themselves, however, there is an urgent need to eradicate the conditions driving alcohol abuse. It is outrageous that a child be given alcohol to quell his hunger before learning to make any decisions themselves. It is a travesty that a child drops out of school in despair and turns to alcohol to numb her pain. Yet these are the daily realities of many indigenous people around the globe.

We are increasingly recognizing our moral obligation to facilitate development of those long deprived of it by removing systematic barriers and redressing wrongs previously committed. Injustice abounds in the indigenous fourth world, in both Canada and Botswana. The first step is to reduce the insurmountable impediment that alcohol abuse is to development and progress. This task is complex and burdensome. Through sharing the challenges and successes already encountered, indigenous populations, and their public health authorities develop solutions more quickly. Through collaboration, governments can be brought to compensate for the wrongs that their first people have endured.

\section{ACKNOWLEDGEMENTS}

This thesis was written as a component of an undergraduate field research course, which took place in southern Africa in August 2009. I would, first and foremost, like to acknowledge my supervisors, Drs. Jacqueline Murray and Alastair Summerlee, for their superb coordination of this life-changing course and their passionate assistance to me in developing and editing this thesis. In addition my thanks go to Nathan Lachowsky and Blair Nameth for their contribution to the planning and coordination of this trip. Thank you to Frisco, Satau, Sabrina Hamilton, and all those at TOCADI and elsewhere in Botswana who contributed to this experience. Thank you also to my peers who accompanied me on this trip - for their feedback on my thesis and the incredible experiences we shared. Finally my thanks must also go to Sally Booth, Laura Jewell, Deb Piggott, Dan Piggott, Robert Piggott, and Allison Webb for their motivation and feedback on my paper.

\section{REFERENCES}

1. Room, R., T. Babor, and J. Rehm. 2005. Alcohol and public health. Lancet, (Feb 5-11): 519-30.

2. Heath, A. C., Et al. 1997. Genetic and environmental contributions to alcohol dependence risk in a national 
twin sample: Consistency of findings in women and men. Psychological Medicine 27, (6) (Nov): 1381-96.

3. Fidler, David. 2001. The globalization of public health: The first 100 years of international health diplomacy. Bulletin of the World Health Organization 79, (9): 8429.

4. Ohenjo, N., R. Willis, D. Jackson, C. Nettleton, K. Good, and B. Mugarura. 2006. Health of indigenous people in Africa. Lancet 367, (9526) (Jun 10): 1937-46.

5. Peele, Stanton, and Marcus Grant, eds. 1999. Alcohol and pleasure: A health perspective. Philadelphia, Pensylvania: Taylor and Francis Group.

6. Molamu, Louis, and Dave MacDonald. 1996. Alcohol abuse among the Basarwa of the Kgalagadi and Ghanzi districts in Botswana. Drugs: Education, Prevention and Policy 3, (2): 145-52.

7. Gujadhur, Tara. 2000. Alcohol abuse intervention strategies for rural (Bushmen) settlements embarking on CBNRM. Gaborone, Botswana: IUCN/SNV CBNRM Support Programme.

8. Le Roux, Willemien. 2000. Torn apart: San children as change agents in a process of acculturation. Shakawe, Botswana: Kuru Development Trust and WIMSA, 2.

9. Lee, Richard. 2009. Lecture at University of Guelph, January 23, 2009.

10. Satau, Gakemotho. 2009. Interview on August 8, 2009.

11. Saugestad, Sidsel. 2001. The inconvenient indigenous. Sweden: The Nordic Africa Institute.

12. Felton, Silke, and Heike Becker. 2001. A gender perspective on the status of the San in southern Africa. Windhoek: Legal Assistance Centre, 5.

13. World Health Organization. 2004. Global status report on alcohol: Botswana. Geneva, Switzerland .

14. World Health Organization. 2005. Botswana: HIV/AIDS treatment. Geneva, Switzerland.

15. Weiser, S. D., Et al. 2006. A population-based study on alcohol and high-risk sexual behaviors in Botswana. PLoS Medicine 3, (10) (Oct): e392.

16. Thatcher, R. W. 2004. Fighting firewater fictions: Moving beyond the disease model of alcoholism in First Nations. Toronto, Canada: University of Toronto Press.

17. Campbell, Robert. 2008. Making sober citizens: The legacy of indigenous alcohol regulation in Canada, 1777-1985. Journal of Canadian Studies 42, (1): 10526.

18. Cairns, Alan. 2000. Citizens plus: Aboriginal peoples and the Canadian state. Vancouver, Canada: UBC Press.

19. Chrétien, Jean. 1969. Statement of the government of Canada on Indian policy. Ottawa, Canada: Government of Canada, http://www.ainc-

inac.gc.ca/ai/arp/ls/pubs/cp1969/cp1969-eng.pdf.

20. Sounds Like Canada - CBC. 2008. February 192008 -

Our home and native land: Dry reserves,

http://www.cbc.ca/aboriginal/2008/02/our_home_and_n ative_land_dry_r/.

21. CBC News. Tuktoyaktuk tries out temporary alcohol ban. 2009c [cited 10/18 2009]. Available from http://www.cbc.ca/canada/north/story/2009/04/15/tukban.html\#socialcomments.

22. CBC News. Alcohol-based sanitizers for flu-hit first nations delayed over substance abuse fears. 2009a [cited 10/10 2009]. Available from http://www.cbc.ca/health/story/2009/06/23/firstnations-swine-flu.html.

23. Health Canada. 2009. A statistical profile on the health of First Nations in Canada. Ottawa, Canada.

24. Adrian, M., N. Layne, and R. T. Williams. 1990. Estimating the effect of native Indian population on county alcohol consumption: The example of Ontario. The International Journal of the Addictions 25, (5A6A) (-1991): 731-65.

25. CBC News. Behchoko residents vote to ban alcohol. 2009b [cited 10/18 2009]. Available from http://www.cbc.ca/canada/north/story/2009/04/16/behc hoko-alcohol.html.

26. CBC The National. Battling the bottle. 2007 [cited 11/20 2009]. Available from http://www.niyc.ca/comment.php?comment.news.410.

27. Deaton, Angus. 2004. Health in the Age of Globalization. National Bureau of Economic Research.

28. Woodward, D., Et al. 2001. Globalization and health: a framework for analysis and action. Bulletin of the World Health Organization 79, (9): 875-81.

29. Rieff, David. 1998. In defense of afro-pessimism. World Policy Journal Winter: 10-22.

30. Room, Robin. 1984. The World Health Organization and alcohol control. British Journal of Addiction 79: 85-91.

31. CBC News. PM cites 'sad chapter' in apology for residential schools. 2008 [cited 11/30 2009]. Available from http://www.cbc.ca/canada/story/2008/06/11/aboriginalapology.html.

32. Bramley, D., Et al. 2005. Disparities in indigenous health: A cross-country comparison between New Zealand and the United States. American Journal of Public Health 95, (5) (May): 844-50. 